\title{
In vitro metabolic engineering for the salvage synthesis of $\mathrm{NAD}^{+}$
}

.

${ }^{1}$ Department of Biotechnology, Graduate School of Engineering, Osaka University, 2-1 Yamadaoka, Suita, Osaka 565-0871, Japan

${ }^{2}$ CREST, Japan Science and Technology Agency (JST), 4-1-8 Honcho Kawaguchi, Saitama 332-0012, Japan

\author{
Kohsuke Honda ${ }^{1,2, *}$, Naoya Hara ${ }^{1}$, Maria Cheng ${ }^{1,2}$,
} Anna Nakamura ${ }^{1}$, Komako Mandai $^{1}$, Kenji Okano $^{1}$, and Hisao Ohtake ${ }^{1}$

8 * Corresponding author: Kohsuke Honda

9 Mailing address, Department of Biotechnology, Graduate School of Engineering, Osaka 20 University, 2-1 Yamadaoka, Suita, Osaka 565-0871, Japan; Phone, +81-6-6879-7438;

21 E-mail address, honda@bio.eng.osaka-u.ac.jp 


\section{Abstract}

24 Excellent thermal and operational stabilities of thermophilic enzymes can greatly 25 increase the applicability of biocatalysis in various industrial fields. However, 26 thermophilic enzymes are generally incompatible with thermo-labile substrates, 27 products, and cofactors, since they show the maximal activities at high temperatures. 28 Despite their pivotal roles in a wide range of enzymatic redox reactions, $\mathrm{NAD}(\mathrm{P})^{+}$and $29 \mathrm{NAD}(\mathrm{P}) \mathrm{H}$ exhibit relatively low stabilities at high temperatures, tending to be a major 30 obstacle in the long-term operation of biocatalytic chemical manufacturing with 31 thermophilic enzymes. In this study, we constructed an in vitro artificial metabolic pathway for the salvage synthesis of $\mathrm{NAD}^{+}$from its degradation products by the combination of eight thermophilic enzymes. The enzymes were heterologously produced in recombinant Escherichia coli and the heat-treated crude extracts of the recombinant cells were directly used as enzyme solutions. When incubated with experimentally optimized concentrations of the enzymes at $60^{\circ} \mathrm{C}$, the $\mathrm{NAD}^{+}$ concentration could be kept almost constant for $15 \mathrm{~h}$. 


\section{Introduction}

43 Enzymes from thermophilic microorganisms exhibit remarkable thermostability and show the maximal activities at high temperatures. In addition, many thermophilic enzymes display higher tolerance towards denaturants, such as detergents and organic solvents, than their mesophilic counterparts (Atomi, 2005; Owusu and Cowan, 1989). Such excellent operational stabilities of thermophilic enzymes can greatly increase the applicability of biocatalysis in various industrial fields, including food processing, biochemical analysis, and chemical manufacturing (Atomi et al., 2011; Bruins et al., 2001). On the other hand, there is an inherent technical limitation in the application of thermophilic enzymes, namely their incompatibility with thermo-labile substrates, products, and cofactors. In particular, the relatively low thermal stabilities of $\mathrm{NAD}(\mathrm{P})^{+}$ and $\mathrm{NAD}(\mathrm{P}) \mathrm{H}$ (Wu et al., 1986) tend to be a major obstacle in the application of thermophilic enzymes. The KEGG database search revealed that nicotinamide cofactors are involved in more than 2000 enzymatic reactions, some of which have already been playing important roles in industrial chemical manufacturing processes (e.g., the enantioselective reductions of prochiral ketones by carbonyl reductases (Kataoka et al., 2003), asymmetric saturations of $\mathrm{C}=\mathrm{C}$ bonds by enoate reductases (Stuermer et al., 2007), and regioselective hydroxylation of non-activated carbon atoms by cytochrome P450 monooxygenases (Urlacher et al., 2004)). In addition, since nicotinamide cofactors can be easily determined spectrophotometrically and electrochemically, they have been widely used as indicator reagents in enzymatic diagnoses and other biochemical analyses (Tachibana et al., 2006; Jena and Raj, 2006). Thus, nicotinamide cofactors have a wide range of practical application and their stabilization is one of the key issues to reinforce the industrial applicability of thermophilic enzymes. Recently, 
we have developed a novel approach to engineer an in vitro artificial metabolic pathway using thermophilic enzymes and demonstrated the one-pot conversion of glucose to lactate (Ye et al., 2012), malate (Ye et al., 2013), and 1-butanol (Krutsakorn et al., 2013). The biocatalytic conversion through the in vitro pathways could be accomplished at sufficient production yields (60-100 mol\%) and conversion rates $\left(0.5-1.2 \mu \mathrm{mol} \mathrm{mL} \mathrm{m}^{-1} \mathrm{~h}^{-1}\right)$. However, despite the use of highly stable enzymes, the bioconversion with these in vitro systems stopped within several hours at $50^{\circ} \mathrm{C}$. The conversion rate could be recovered by the re-addition of $\mathrm{NAD}^{+}$and/or $\mathrm{NADH}$ to the reaction mixture, clearly indicating that the thermal decomposition of these cofactors hampered the long-term implementation of the in vitro bioconversion (Ye et al., 2012; Krutsakorn et al., 2013). Zhang and coworkers (2014a) demonstrated that an in vitro hydrogen production system could be operated for $90 \mathrm{~h}$ at $40^{\circ} \mathrm{C}$ under anaerobic conditions; however, they also reported that increase in the reaction temperature to $60^{\circ} \mathrm{C}$ resulted in a considerable decrease in the operational stability of their system (Rollin et al., 2014b). Similarly, Wu et al. (2011) reported that the kinetic resolution of $(R S)$-phenylethanol using an enzyme couple of thermostable $\mathrm{NAD}^{+}$-dependent alcohol dehydrogenase and NADH oxidase gave an insufficient conversion yield at a high temperature owing to the instability of $\mathrm{NAD}(\mathrm{H})$. Since these cofactors are generally expensive, their stabilization and long-term use is a crucial challenge to developing an economically feasible biotransformation process with thermophilic enzymes. Replacement of the natural redox cofactors with stable and inexpensive biomimetic analogs has been proposed as a possible solution to this problem (Rollin et al., 2013). Yet, the $k_{\mathrm{cat}} / K_{\mathrm{m}}$ of natural enzymes for these compounds are 1-3 orders of magnitude lower than those for natural cofactors (Ansell Lowe, 1999), indicating that protein engineering efforts are 

al., 2013).

These limitations motivated us to develop an alternative approach for the long-term use of the redox cofactors at high temperatures. The thermally unstable nature of nicotinamide cofactors generates a demand for the molecular apparatus for salvaging their degradation products in thermophilic microorganisms. Thus, these microorganisms would seem to be equipped with a series of enzymes involved in the resynthesis of the cofactors from their degradants. Identification and assembly of these enzymes enable us to construct an in vitro pathway for the salvage synthesis of the cofactors. In this study, we focused on $\mathrm{NAD}^{+}$and constructed an in vitro salvage synthetic pathway of the cofactor using thermophilic enzymes.

\section{Materials and methods}

2.1. Reagents. $\mathrm{NAD}^{+}, \mathrm{NADH}, \mathrm{NADP}^{+}, \mathrm{ATP}, \mathrm{ADP}$, and $\mathrm{AMP}$ were obtained from Oriental Yeast (Osaka, Japan). Nicotinamide, ADP-ribose, and other intermediates were purchased from Sigma-Aldrich Japan (Tokyo, Japan). Thermotolerant glucose-1-dehydrogenase (GDH; code number, GCD-41-01) and glucose-6-phosphate dehydrogenase (G6PDH; code number, GLD-75-01) were products of Thermostable Enzyme Laboratory (Kobe, Japan). Polyphosphate was chemically synthesized as follows: $35 \mathrm{~g}$ of $\mathrm{NaH}_{2} \mathrm{PO}_{4}$ (anhydrous, Wako Pure Chemical, Osaka, Japan) and $0.3 \mathrm{~g}$ of

$111 \mathrm{Na}_{2} \mathrm{HPO}_{4}$ (anhydrous, Wako Pure Chemical) were mixed by grinding in a mortar. The 112 mixture was placed in a platinum pot and heated at $800^{\circ} \mathrm{C}$ for $150 \mathrm{~min}$ in an electric 113 furnace. The resulting glassy material was used as polyphosphate. 
115 2.2. Expression plasmids for thermophilic enzymes. The expression plasmids 116 encoding nicotinate mononucleotide adenylyltransferase ( $\mathrm{NaMAT}_{\mathrm{Tt}}$; gi|55981749), 117 nicotinate phosphoribosyltransferase $\quad\left(\mathrm{NaPRT}_{\mathrm{Tt}} ; \quad\right.$ gi|55980586), $\quad$ ADP-ribose 118 pyrophosphatase $\left(\mathrm{ADPRP}_{\mathrm{Tt}} ;\right.$ gi|29603631), ribose-phosphate pyrophosphokinase $119\left(\mathrm{RPK}_{\mathrm{Tt}} ;\right.$ gi|55981518), and adenylate kinase $\left(\mathrm{ADK}_{\mathrm{Tt}}\right.$; gi|55981640) were obtained from 120 the RIKEN Thermus thermophilus HB8 expression plasmid library (Yokoyama et al, 121 2000). The expression vectors for pyruvate kinase (gi| 55979972), lactate dehydrogenase (gi|55981082), and glucokinase (gi|55980268) from T. thermophilus HB8, which were used for the determination of the activities of $\mathrm{ADK}_{\mathrm{Tt}}$ and polyphosphate kinase from T. thermophilus HB27 (PPK $\mathrm{Pt}_{\mathrm{Tt}}$ gi|46198945), were also obtained from the same library. The codon-optimized genes encoding $\mathrm{NAD}^{+}$synthase from T. thermophilus HB8 (NADS $\mathrm{Tt}$; gi|55981869) and that from Bacillus stearothermophilus $\left(\mathrm{NADS}_{\mathrm{Bs}}\right.$; gi|696475119) were synthesized by GeneArt

128 (Regensburg, Germany) and introduced to the NdeI/XhoI restriction sites of pET21a 129 (Novagen, Madison, WI, USA). The gene coding for nicotinamidase from 130 Thermoplasma acidophilum (NADase $\mathrm{Ta}$; gi|499203341) was amplified by PCR using 131 the chromosomal DNA of $T$. acidophilum NBRC15155 with the following 132 oligonucleotide primers: 5'-cccatatgaaactgcacttgtagttgtggaca-3' (the NdeI restriction 133 site is underlined), and 5' -ggaagcttctacgtctctatctgatcttcctgc-3' (the BamHI restriction 134 site is underlined). The PCR amplicon was digested with NdeI and BamHI, and then 135 introduced to the corresponding site of pET21a. The expression vector for $\mathrm{PPK}_{\mathrm{Tt}} \mathrm{Was}$ 136 constructed as described elsewhere (Iwamoto et al., 2007). E. coli Rosetta2 (DE3) 137 (Novagen) was used as the host strain for gene expression. Recombinant cells were 
cultivated aerobically at $37^{\circ} \mathrm{C}$ in Luria-Bertani (LB) medium supplemented with $50 \mu \mathrm{g}$

$139 \mathrm{ml}^{-1}$ ampicillin and $30 \mu \mathrm{g} \mathrm{ml}^{-1}$ chloramphenicol. Isopropyl- $\beta$-D-1-thiogalactopyranoside 140 (IPTG) was added to the culture at a final concentration of $0.2 \mathrm{mM}$ in the late-log phase.

141 The cells were further cultivated for $4 \mathrm{~h}$. The cells were then harvested by centrifugation 142 at $6,500 \times g$ and $4^{\circ} \mathrm{C}$ for $10 \mathrm{~min}$ and washed once with $100 \mathrm{mM}$ HEPES-NaOH buffer $143(\mathrm{pH} 8.0)$.

145 2.3. Enzyme assays. Recombinant cells were suspended in an appropriate volume of 100 mM HEPES-NaOH (pH 8.0) and disrupted using a UD-201 ultrasonicator (TOMY,

147 Osaka, Japan) at $20 \mathrm{~W}$ for $2 \mathrm{~min}$. Cell debris was removed by centrifugation at $12,000 \times$ $g$ at $4^{\circ} \mathrm{C}$ for $10 \mathrm{~min}$. The protein concentration in the crude lysates was measured by the Bradford assay using bovine serum albumin as the standard. The Bio-Rad assay system (Bio-Rad, Hercules, CA, USA) was used for protein determination. The resulting crude lysates were incubated at $70^{\circ} \mathrm{C}$ for 30 min to inactivate the host-derived enzymes and centrifuged again to remove denatured proteins. The supernatants were obtained as enzyme solutions. When necessary, the obtained enzyme solutions were concentrated using Amicon Ultra 10K (Merck Millipore, Darmstadt, Germany).

155 Enzyme activity was determined spectrophotometrically at $60^{\circ} \mathrm{C}$ in the basal buffer consisting of $400 \mathrm{mM}$ HEPES-NaOH (pH 8.0), $60 \mathrm{mM} \mathrm{NH} 4 \mathrm{Cl}, 10 \mathrm{mM} \mathrm{MgCl}_{2}$, and 1 $\mathrm{mM}$ polyphosphate. NADase $\mathrm{Ta}_{\mathrm{T}}$ activity was assessed by incubating the enzyme at an appropriate amount in the basal buffer supplemented with $0.2 \mathrm{mM}$ ATP, $0.2 \mathrm{mM}$ phosphoribosyl pyrophosphate (PRPP), $1 \mathrm{mM}$ glucose, and excess amounts of $\mathrm{NaPRT}_{\mathrm{Tt}}$, $\mathrm{NaMAT}_{\mathrm{Tt}}, \mathrm{NADS}_{\mathrm{Bs}}$, and GDH. After the preincubation at $60^{\circ} \mathrm{C}$ for $2 \mathrm{~min}$, the reaction was started by adding nicotinamide at a final concentration of $0.2 \mathrm{mM}$ and the 
formation of NADH was monitored at $340 \mathrm{~nm}$. Similarly, the activity of $\mathrm{NaPRT}_{\mathrm{Tt}}$ was determined by coupling the enzyme with excess amounts of $\mathrm{NaMAT}_{\mathrm{Tt}}, \mathrm{NADS}_{\mathrm{Bs}}$, and $\mathrm{GDH}$, and using $0.2 \mathrm{mM}$ nicotinate as the substrate. $\mathrm{NaMAT}_{\mathrm{Tt}}$ and $\mathrm{NADS}_{\mathrm{Bs}}$ activities were assessed similarly using $0.2 \mathrm{mM}$ each of their substrate (NaMN and deamino-NAD ${ }^{+}$, respectively) except that PRPP was not added to the reaction mixture. $\mathrm{ADPRP}_{\mathrm{Tt}}$ activity was spectrophotometrically assessed by coupling with $\mathrm{RPK}$, $\mathrm{NaPRT}_{\mathrm{Tt}}, \mathrm{NaMAT}_{\mathrm{Tt}}, \mathrm{NADS}_{\mathrm{Bs}}$, and GDH. The enzymes were precincubated at $60^{\circ} \mathrm{C}$ in the basal buffer containing $0.2 \mathrm{mM}$ ATP, $0.2 \mathrm{mM}$ nicotinate, and $1 \mathrm{mM}$ glucose. The reaction was initiated by adding $0.2 \mathrm{mM}$ ADP-ribose and monitored at $340 \mathrm{~nm}$. RPK assay was performed in the same manner using $0.2 \mathrm{mM}$ ribose-5-phosphate $(\mathrm{R} 5 \mathrm{P})$ as the substrate. $\mathrm{ADK}_{\mathrm{Tt}}$ activity was determined by the coupling reaction with pyruvate kinase and lactate dehydrogenase from T. thermophilus $\mathrm{HB} 8 . \mathrm{ADK}_{\mathrm{Tt}}$ at an appropriate amount was coincubated with excess amounts of the coupling enzymes in the basal buffer containing $0.2 \mathrm{mM}$ AMP, $0.2 \mathrm{mM}$ phosphoenolpyruvate, and $0.2 \mathrm{mM} \mathrm{NADH}$. After the preincubation for $2 \mathrm{~min}$, the reaction was started by adding $0.2 \mathrm{mM}$ ATP and then the consumption rate of $\mathrm{NADH}$ was monitored at $340 \mathrm{~nm}$. $\mathrm{PPK}_{\mathrm{Tt}}$ activity was assessed through the coupling reaction with thermotolerant glucokinase and G6PDH. The enzymes were incubated in the buffer containing $0.2 \mathrm{mM}$ ADP, $0.2 \mathrm{mM}$ glucose, and 0.2 $\mathrm{mM} \mathrm{NADP}^{+}$. The NADPH formation rate accompanied by the oxidation of glucose-6-phosphate by G6PDH was monitored at $340 \mathrm{~nm}$.

182 The millimolar extinction coefficient of $6.2 \mathrm{mM}^{-1} \mathrm{~cm}^{-1}$ was employed for the determination of NADH and NADPH concentrations at $340 \mathrm{~nm}$. One unit (U) of enzyme was defined as the amount catalyzing the consumption of $1 \mu$ mol of the substrate per minute under the assay conditions. 
187 2.4. In vitro salvage synthesis of $\mathrm{NAD}^{+}$. The reaction mixture was composed of 400 mM HEPES-NaOH (pH8.0), $60 \mathrm{mM} \mathrm{NH} 4 \mathrm{Cl}, 10 \mathrm{mM} \mathrm{MgCl}_{2}, 1 \mathrm{mM}$ polyphosphate, 3 mM ATP, and 4 mM NAD ${ }^{+}$. NADase ${ }_{\mathrm{Ta}}, \mathrm{NaPRT}_{\mathrm{T}}, \mathrm{NaMAT}_{\mathrm{T}}, \mathrm{NADS}_{\mathrm{Bs}}, \mathrm{ADPRP}_{\mathrm{Tt}}, \mathrm{RPK}_{\mathrm{Tt}}$,

$190 \mathrm{ADK}_{\mathrm{Tt}}$, and $\mathrm{PPK}_{\mathrm{Tt}}$ were put in the reaction mixture at final concentrations of 0.006 , 0.052, 0.08, 0.5, 0.006, 0.02, 0.02, and $0.08 \mathrm{U} \mathrm{ml}^{-1}$, respectively (Supplementary Table $\mathrm{S} 1)$. The mixture with a final volume of $5 \mathrm{ml}$ was incubated at $60^{\circ} \mathrm{C}$. An aliquot was sampled at specific intervals and ultrafiltrated with Amicon Ultra $10 \mathrm{~K}$ (Merck Millipore). The filtrate was analyzed by HPLC.

195

2.5. Analytical methods. $\mathrm{NAD}^{+}, \mathrm{ADP}-$ ribose, nicotinamide, nicotinate, $\mathrm{NaMN}$, deamino-NAD ${ }^{+}$, AMP, ADP, and ATP were analyzed by HPLC on a Cosmosil $5 \mathrm{C}_{18}$-ARII column $(\phi 4.6 \times 250 \mathrm{~mm}$, Nacalai Tesque, Kyoto, Japan $)$. The mobile phase was composed of (A) $50 \mathrm{mM}$ potassium phosphate buffer (pH 6.0) and (B) $25 \%(\mathrm{v} / \mathrm{v})$ methanol containing $5 \mathrm{mM}$ 1-sodium 1-octanesulfonate. The column was eluted with mobile phase A for the initial 5 min and then the volumetric ratio of mobile phase B was increased from 0 to $100 \%$ in the following 6 min. The column was further eluted only with mobile phase $\mathrm{B}$ for $6 \mathrm{~min}$. The column temperature was maintained at $40^{\circ} \mathrm{C}$ and the total flow rate of the mobile phases was kept at $1.0 \mathrm{ml} \mathrm{min}^{-1}$. The eluent was analyzed with a SPD-20AV UV-VIS detector (Shimadzu) at $254 \mathrm{~nm}$.

\section{Results}

\subsection{Identification of the thermal degradation products of $\mathrm{NAD}^{+}$}


The decomposition of the oxidized nicotinamide cofactors, $\mathrm{NAD}^{+}$and $\mathrm{NADP}^{+}$, starts

211 from a base-catalyzed hydrolysis of the $\mathrm{C}-\mathrm{N}$ bond between nicotinamide and ribose moieties (Chenault and Whitesides, 1987). HPLC analysis of the degradation products of $\mathrm{NAD}^{+}$at $\mathrm{pH} 8.0$ gave two major peaks and their retention times were identical to

214 those of authentic nicotinamide and ADP-ribose. These compounds almost 215 stoichiometrically accumulated in accordance with the degradation of $\mathrm{NAD}^{+}$(Fig. 1) 216 although a trace amount of nicotinamide, which was likely to be an impurity in the 217 commercial $\mathrm{NAD}^{+}$, was detected even at time zero. This observation indicated that nicotinamide and ADP-ribose are relatively stable at high temperatures. In fact, no significant degradation was observed for at least $6 \mathrm{~h}$ when nicotinamide and ADP-ribose were incubated at $60^{\circ} \mathrm{C}$ and pH8.0 (Supplementary Fig. S1). Based on these results, we selected these compounds as the initial substrates for the salvage synthesis of NAD ${ }^{+}$

\subsection{Enzymes involved in nicotinamide salvage}

The single-gene-expression library of Thermus thermophilus HB8 (Yokoyama et al., 2000) was employed as a primary source of the genes encoding thermophilic enzymes. The enzymes that are likely involved in the nicotinamide salvage were selected on the basis of the annotation data of the T. thermophilus HB8 genome and then assayed to confirm their capability to catalyze expected reactions (Fig. 2, Supplementary Fig. S2). The enzyme assay revealed that the nicotinate mononucleotide adenylyltransferase of $T$. thermophilus $\mathrm{HB} 8\left(\mathrm{NaMAT}_{\mathrm{Tt}}\right)$ can use both nicotinamide mononucleotide $(\mathrm{NMN})$ and nicotinate mononucleotide $(\mathrm{NaMN})$ as substrates and catalyze their adenylylation to $\mathrm{NAD}^{+}$and deamino-NAD ${ }^{+}$, respectively. The specific enzyme activities in the crude extract of recombinant $E$. coli with $\mathrm{NaMAT}_{\mathrm{Tt}}$ were estimated to be 0.177 and $3.72 \mathrm{U}$ 
$234 \mathrm{mg}^{-1}$ total protein for NMN and NaMN, respectively. By contrast, although nicotinate 235 phosphoribosyltransferase $\left(\mathrm{NaPRT}_{\mathrm{Tt}}\right)$ catalyzed the phosphoribosylation of nicotinate to 236 NaMN using PRPP, nicotinamide did not serve as the substrate of the enzyme. NAD ${ }^{+}$ 237 synthase from $T$. thermophilus $\mathrm{HB} 8\left(\mathrm{NADS}_{\mathrm{Tt}}\right)$ catalyzed the $\mathrm{NH}_{3}$-dependent amination 238 of deamino-NAD ${ }^{+}$to $\mathrm{NAD}^{+}$. The enzyme required ATP as an energy cofactor and 239 released AMP. However, the specific activity of $\mathrm{NADS}_{\mathrm{Tt}}$ in the recombinant E. coli $240\left(5.48 \times 10^{-4} \mathrm{U} \mathrm{mg}^{-1}\right.$ total protein) was considerably lower than those of other enzymes, 241 such as NaMAT $_{\mathrm{Tt}}$ and $\mathrm{NaPRT}_{\mathrm{Tt}}\left(4.12 \times 10^{-2} \mathrm{U} \mathrm{mg}^{-1}\right.$ total protein $)$, under the standard 242 conditions. Therefore, a literature search was done to find another thermophilic NAD ${ }^{+}$ 243 synthase and that from Bacillus stearothermophilus $\left(\mathrm{NADS}_{\mathrm{Bs}}\right)$ was identified 244 (Yamaguchi et al., 2002). The desired enzyme activity was found in the crude extract of the recombinant $E$. coli having $\mathrm{NADS}_{\mathrm{Bs}}$ and the specific activity was determined to be $0.19 \mathrm{U} \mathrm{mg}^{-1}$ total protein.

By this method, we identified some thermophilic enzymes involved in the salvage synthesis of $\mathrm{NAD}^{+}$; however, those to be engaged in the initial reactions of nicotinamide salvage, namely, phosphoribosylation to NMN and deamination to nicotinate, were not

250 found in the annotation data of the T. thermophilus HB8 genome. Among the 251 bacterial/archaeal enzymes, nicotinamide phosphoribosyltransferase (NPRT) from Haemophilus ducreyi has been demonstrated to catalyze the phosphoribosylation of nicotinamide to NMN (Martin et al., 2001). However, BLAST searches of the genomic sequences of $T$. thermophilus and other thermophiles yielded no hits when the amino acid sequence of $H$. ducreyi NPRT was used as a query. Indeed, the comparative genomics analysis by Gazzaniga et al. (2000) suggests that genes encoding putative NPRT are conserved only in a limited number of animals, bacteria, and viruses, but not 
in thermophilic microorganisms. On the other hand, nicotinamidase, the enzyme catalyzing the deamination of nicotinamide to nicotinate, has been isolated from some thermophilic archaea, such as Acidilobus saccharovorans (Stekhanova et al., 2014), Pyrococcus horikoshii (Du et al., 2001), and Thermoplasma acidophilum (Luo et al., 2010). We cloned and expressed the gene encoding nicotinamidase from T. acidophilum (NADase $_{\mathrm{Ta}}$ ) and confirmed its activity (Fig. S2). The specific activity of NADase $\mathrm{Ta}_{\mathrm{Ta}}$ in the crude extract of the recombinant $E$. coli was $0.11 \mathrm{U} \mathrm{mg}^{-1}$ total protein. Thus, we employed the four-step pathway, consisting of deamination, phosphoribosylation, adenylylation, and reamination, for the in vitro salvage of nicotinamide (Fig. 2).

\subsection{ADP-ribose salvage and regeneration of ATP from AMP}

ADP-ribose pyrophosphatase $\left(\mathrm{ADPRP}_{\mathrm{Tt}}\right)$, which is engaged in the initial reaction of ADP-ribose salvage, from T. thermophilus HB8 has been well characterized with respect to its structure and function (Ooga et al., 2005; Yoshiba et al., 2004). We also verified that the recombinant $\mathrm{ADPRP}_{\mathrm{Tt}}$ expressed in $E$. coli can catalyze the hydrolysis of ADP-ribose (Fig. S2). The reaction products, i.e., R5P and AMP, should be subsequently pyrophosphorylated for salvaging in $\mathrm{NAD}^{+}$synthesis. The ribose-phosphate pyrophosphokinase from T. thermophilus HB8 $\left(\mathrm{RPK}_{\mathrm{Tt}}\right)$ was selected for the pyrophosphorylation of R5P to PRPP and its activity was confirmed by a coupling reaction with $\mathrm{NaPRT}_{\mathrm{Tt}}$. When these enzymes were coincubated with R5P, ATP, and nicotinate, NaMN formation was observed (Fig. S2). The in vitro pathway for the salvage synthesis of $\mathrm{NAD}^{+}$from nicotinamide and ADP-ribose is illustrated in Fig. 3. For the synthesis of one molecule of NAD ${ }^{+}$through the designed pathway, two molecules of ATP are required as phosphate and energy 
sources in the reaction catalyzed by $\mathrm{RPK}_{\mathrm{Tt}}$ and $\mathrm{NADS}_{\mathrm{Bs}}$, respectively. In addition, AMP

283

284

285

released by $\mathrm{ADPRP}_{\mathrm{Tt}}$ should also be pyrophosphoryrated to be recycled as an adenylyl donor of $\mathrm{NaMAT}_{\mathrm{Tt}}$ reaction. Therefore, an ATP-regenerating system should be integrated into the in vitro pathway for the continuous recycling of the adenylate moieties. Polyphosphate is often used as an inexpensive phosphate donor in in vitro ATP regeneration and several polyphosphate-dependent enzymatic systems for the pyrophosphorylation of AMP to ATP have been reported (Kameda et al., 2001; Resnick and Zehnder, 2000; Satoh et al., 2004). We employed a coupling reaction of adenylate kinase and polyphosphate kinase (Satoh et al., 2004) owing to the well-characterized feature of the thermostable polyphosphate kinase from T. thermophilus $\mathrm{HB} 27\left(\mathrm{PPK}_{\mathrm{Tt}}\right)$ (Iwamoto et al., 2007). The thermophilic adenylate kinase $\left(\mathrm{ADK}_{\mathrm{Tt}}\right)$ was obtained from the gene-expression library of T. thermophilus HB8 and used as the coupling partner.

The thermal stabilities of the enzymes involved in the designed pathway are shown in Fig. S3. Although $\mathrm{NADS}_{\mathrm{Bs}}$ and $\mathrm{RPK}_{\mathrm{Tt}}$ lost $50 \%$ of their activity after the incubation at $60^{\circ} \mathrm{C}$ for $12 \mathrm{~h}$, other enzymes retained more than $75 \%$ activity upon the heat treatment under the same conditions.

\subsection{In vitro salvage synthesis of $\mathrm{NAD}^{+}$}

$\mathrm{NAD}^{+}$is relatively stable at an acidic $\mathrm{pH}$ while its reduced derivative, $\mathrm{NADH}$, is more stable under alkaline conditions (Chenault and Whitesides 1987). Therefore, by stabilizing $\mathrm{NAD}^{+}$at an alkaline $\mathrm{pH}$, both oxidized and reduced forms of the cofactor can be stably maintained. On the basis of this assumption, we employed a reaction $\mathrm{pH}$ of 8.0 for the implementation of the in vitro salvage synthesis of $\mathrm{NAD}^{+}$. 
The heat-treated $\left(70^{\circ} \mathrm{C}\right.$ for $\left.30 \mathrm{~min}\right)$ crude extracts of recombinant E. coli with thermophilic enzymes were directly used as catalysts for the in vitro salvage synthesis

307 (Supplementary Fig. S4). The flux through the in vitro pathway (i.e., NAD ${ }^{+}$production rate) was monitored in a real-time manner by spectrophotometric assays. NAD ${ }^{+}$ produced through the pathway was concomitantly reduced with a thermotolerant glucose dehydrogenase (GDH) and the formation of NADH was monitored at $340 \mathrm{~nm}$. This real-time monitoring technique enabled us to experimentally optimize the enzyme concentration to achieve a desired flux. To achieve $\mathrm{NAD}^{+}$production from nicotinamide at a rate of $0.006 \mu \mathrm{mol} \mathrm{ml} \mathrm{m}^{-1} \mathrm{~min}^{-1}$, which is identical to the initial degradation rate of

$314 \mathrm{NAD}^{+}$at $\mathrm{pH} 8.0$ and $60^{\circ} \mathrm{C}$ (Fig. 1), we first used $0.006 \mathrm{U} \mathrm{ml}^{-1}$ each of NADase ${ }_{\mathrm{Ta}}$, $\mathrm{NaPRT}_{\mathrm{Tt}}, \mathrm{NaMAT}_{\mathrm{T}}$, and $\mathrm{NADS}_{\mathrm{Bs}}$. The $\mathrm{NAD}^{+}$production rate observed under these conditions was, however, considerably lower than the expected value. In an in vitro reconstituted pathway, the actual concentrations of intermediates are kept lower than those used under the standard assay conditions (Krutsakorn et al., 2013). Consequently, the reaction rates of the enzymes, particularly those with high $K_{\mathrm{m}}$ values for their substrates, are lower than those observed under the standard assay conditions. The rate-limiting enzymes in the $\mathrm{NAD}^{+}$synthetic pathway could be identified by increasing the concentration of each enzyme in the spectrophotometer cuvette, one by one. The concentration of an identified enzyme was then increased in a stepwise manner until the $\mathrm{NAD}^{+}$production rate no longer increased. Subsequently, the next rate-limiting enzyme was identified and its concentration was modulated in the same manner. These procedures were repeated until the $\mathrm{NAD}^{+}$production rate through the cascade reaction reached $0.006 \mu \mathrm{mol} \mathrm{ml} \mathrm{min}^{-1}$. As a result, the optimum concentrations of NADase $\mathrm{Ta}_{\mathrm{Ta}}$ $\mathrm{NaPRT}_{\mathrm{Tt}}, \mathrm{NaMAT}_{\mathrm{Tt}}$, and $\mathrm{NADS}_{\mathrm{Bs}}$ for the nicotinamide salvage were determined to be 

of $\mathrm{ADPRP}_{\mathrm{Tt}}$ and $\mathrm{RPK}_{\mathrm{Tt}}$ were determined to be 0.006 , and $0.01 \mathrm{U} \mathrm{ml}^{-1}$, respectively, by using the above-mentioned concentrations of $\mathrm{NaPRT}_{\mathrm{Tt}}, \mathrm{NaMAT}_{\mathrm{T}}$, and $\mathrm{NADS}_{\mathrm{Bs}}$. The rate of ATP production catalyzed by $\mathrm{PPK}_{\mathrm{Tt}}$ was also spectrophotometrically determined by coupling the enzyme with glucokinase from $T$. thermophilus and a thermotolerant 334 glucose-6-phosphate dehydrogenase (G6PDH) and by monitoring the NADPH production rate through the cascade reaction. For the spectrophotometric determination of ADP production rate with $\mathrm{ADK}_{\mathrm{T}}$, the enzyme was coupled with pyruvate kinase and lactate dehydrogenase from $T$. thermophilus. For the salvage synthesis of $\mathrm{NAD}^{+}$, excess concentrations of $\mathrm{ADK}_{\mathrm{Tt}}$ and $\mathrm{PPK}_{\mathrm{Tt}}$ were used (0.02, and $0.08 \mathrm{U} \mathrm{ml}^{-1}$, respectively) to ensure that the rate of salvage synthesis is not limited by the regeneration rate of ATP. In addition to their crucial roles in cellular redox reactions, nicotinamide cofactors are involved in many biologically important reactions, such as ADP ribosylation of proteins (Gill et al., 1969), sirturin-mediated deacetylation of protein lysine (Imai et al., 2000), and bacterial DNA ligation (Wilkinson et al., 2001). These facts imply that the intracellular concentrations of nicotinamide cofactors are tightly controlled in living organisms by regulating their biosynthetic enzymes at transcriptional, translational, and post-translational levels. We investigated whether the activities of enzymes involved in our salvage pathway are allosterically modulated by $\mathrm{NAD}^{+}$and found that $\mathrm{NaPRT}_{\mathrm{Tt}}$ was inhibited by a high concentration of $\mathrm{NAD}^{+}$(Fig. 4). In the presence of $4 \mathrm{mM} \mathrm{NAD}^{+}$, $\mathrm{NaPRT}_{\mathrm{Tt}}$ lost nearly $60 \%$ of its original activity. Accordingly, in the in vitro reconstituted pathway, $\mathrm{NaPRT}_{\mathrm{Tt}}$ was used at a fourfold higher concentration than that determined on the basis of the spectrophotometric assay. Besides $\mathrm{NaPRT}_{\mathrm{Tt}}$, the 
concentrations of NADS ${ }_{\mathrm{Bs}}$ and $\mathrm{RPK}_{\mathrm{Tt}}$ were doubled by taking into consideration their relatively low thermal stability (Fig. S3).

To demonstrate the in vitro salvage synthesis of $\mathrm{NAD}^{+}$, the enzymes at their optimized concentrations (Supplementary Table S1) were incubated at $60^{\circ} \mathrm{C}$ with $4 \mathrm{mM} \mathrm{NAD}{ }^{+}$ (Fig. 5). NAD ${ }^{+}$concentration was kept almost constant in the presence of the salvage enzymes for $15 \mathrm{~h}$ although that in the control experiments without the enzymes decreased to $0.9 \mathrm{mM}$ after the incubation for the same period.

\section{Discussion}

In this study, we identified the series of thermophilic enzymes involved in the salvage synthesis of $\mathrm{NAD}^{+}$from its thermal degradation products, nicotinamide and ADP-ribose. We then assembled the enzymes to construct an in vitro salvage synthetic pathway of the cofactor. By the integration of the in vitro pathway, the degradation of $\mathrm{NAD}^{+}$at a high temperature could be apparently prevented for $15 \mathrm{~h}$. After the reaction for $15 \mathrm{~h}$, decrease in $\mathrm{NAD}^{+}$concentration accompanied by the accumulation of AMP became significant (Supplementary Fig S5). This observation indicated that the salvage synthesis stopped most probably due to the arrest of the ATP regeneration. The salvage synthesis of $\mathrm{NAD}^{+}$is an energetically expensive reaction owing to the involvement of several water-releasing condensation steps (i.e., those catalyzed by $\mathrm{RPK}_{\mathrm{Tt}}, \mathrm{NaPRT}_{\mathrm{Tt}}$, $\mathrm{NaMAT}_{\mathrm{Tt}}$, and NADS $\mathrm{Bs}_{\mathrm{B}}$ ) and thus requires a continuous supply of ATP. Meanwhile, the ATP-regenerating enzymes, $\mathrm{ADK}_{\mathrm{Tt}}$ and $\mathrm{PPK}_{\mathrm{Tt}}$, exhibited relatively high thermal stability (Fig S3). In addition, we used these enzymes at excess concentrations to maintain the higher rate of ATP regeneration than that of $\mathrm{NAD}^{+}$-salvage synthesis. These facts imply that the arrest of the ATP regeneration is more likely due to the 
depletion of polyphosphate rather than the thermal inactivation of the enzymes. On the

377 other hand, increased concentration of polyphosphate tends to inhibit the activities of metal-dependent enzymes owing to its chelating ability (Restiawaty et al., 2011). Therefore, addition of polyphosphate in a fed-batch manner would be effective to 380 prolong the endurance time of the salvage synthesis of $\mathrm{NAD}^{+}$.

381 While the in vitro salvage synthesis of $\mathrm{NAD}^{+}$can be a promising approach to extent the 382 operational stability of biocatalytic conversion with thermophilic enzymes, the series of 383 enzymes consisting of the in vitro pathway had to be separately prepared in this study.

384 This time-consuming operation would be skipped by the coexpression of multiple genes encoding the series of thermophilic enzymes in a single recombinant strain. Recently, we constructed an artificial operon encoding nine thermophilic enzymes consisting of a non-ATP-forming glycolytic pathway and coexpressed them in a single recombinant $E$. coli (Ninh et al., 2015). The expression levels of thermophilic genes were controlled by modulating their sequential order in the operon. A simple heat-treatment of the crude extract of the resulting coexpression cells led to a one-step preparation of the cocktail of

391 the thermophilic enzymes, which could be directly used for in vitro bioconversion of 392 glucose to pyruvate and lactate. Similarly, development of a multiple-gene-expression 393 strain harboring the thermophilic $\mathrm{NAD}^{+}$synthetic enzymes would markedly increase the 394 feasibility of the in vitro salvage synthetic system. Construction of the coexpression strain and its integration to another in vitro bioconversion pathway for chemical manufacturing is now in progress.

397 Another crucial challenge would be a construction of the salvage synthetic pathway for 398 the phosphorylated derivative of the cofactor, $\mathrm{NADP}^{+}$, as well as those for reduced 399 forms of nicotinamide cofactors. Ben-Hayyim et al. (1967) reported that the thermal 
degradation of $\mathrm{NADP}^{+}$proceeds analogously to that of $\mathrm{NAD}^{+}$. Accordingly, 2'-phosphorylated ADP-ribose and nicotinamide are generated as degradants of NADP ${ }^{+}$. This fact indicates that the salvage synthesis of $\mathrm{NADP}^{+}$can likely be achieved with a similar enzyme system, which may involve an extra enzyme set for 2'-dephosphorylation and rephosphorylation of ADP-ribose 2'-phosphate.

On the other hand, completely different mechanisms have been proposed for the degradation of the reduced forms of nicotinamide cofactors. According to a conventionally accepted model, NADH decomposition involves hydration, epimerization, and cyclization; consequently, cyclic 1,4,5,6-tetrahydronicotinamide adenine dinucleotide (cTHNAD) is formed as the degradation product (Chenault and Whitesides, 1987). More recently, Hofmann et al. (2010) used mass spectrometry to investigate the thermal degradation of $\mathrm{NAD}(\mathrm{P}) \mathrm{H}$. Based on the results of their spectrometric analyses, they postulated that the degradation of reduced forms of nicotinamide cofactors proceeds via the oxidative ring-opening of a ribose moiety, release of nicotinamide, and dehydration. As a result, an ADP derivative with an 415 incomplete ribose ring is generated. To our knowledge, enzymes involved in the 416 metabolisms of these degradation products have not yet been reported, indicating that 417 the in vitro salvage synthesis of $\mathrm{NAD}(\mathrm{P}) \mathrm{H}$ will be a more difficult challenge than that of 418 the oxidized cofactors. However, the markedly high growth temperatures of 419 thermophiles suggest the presence of unidentified enzyme systems for the salvage of 420 these thermal degradation products for managing the thermo-labilities of NAD(P)H. 421 The comprehensive elucidation of the salvage synthetic routes of nicotinamide cofactors 422 in thermophiles would be an important issue for not only the biotechnological purposes 
423 but also a deeper understanding of the underlying mechanisms in the unique physiology 424 of thermophilic microorganisms.

425

426 Acknowledgements

427 This work was in part supported by the Japan Science and Technology Agency (JST),

428 PRESTO and CREST programs. This work was also partly supported by the Japan

429 Society for the Promotion of Science (JSPS), KAKENHI Grant (26450088). We thank

430 Dr. Atomi Haruyuki, Kyoto University, for thoughtful discussion on thermophilic 431 enzymes.

432

433

434

435 


\section{References}

Ansell RJ, Lowe CR (1999) Artificial redox coenzymes: biomimetic analogues of $\mathrm{NAD}^{+}$. Appl Microbiol Biotechnol 51: 703-710.

Atomi H (2005) Recent progress towards the application of hyperthermophiles and their enzymes. Curr Opin Chem Biol 9: 166-173.

Atomi H, Sato T, Kanai T (2011) Application of hyperthermophiles and their enzymes. Curr Opin Biotechnol 22: 618-626.

Ben-Hayyim G, Hochman A, Avron M (1967) Phosphoadenosine diphosphate ribose, a specific inhibitor of nicotinamide adenine dinucleotide phosphate enzymes. J Biol Chem 242: 2837-2839.

Bruins ME, Janssen AE, Boom RM (2001) Thermozymes and their applications: a review of recent literature and patents. Appl Biochem Biotechnol 90: 155-186.

Chenault HK, Whitesides GM (1987) Regeneration of nicotinamide cofactors for use in organic synthesis. Appl Biochem Biotechnol 14: 147-197.

Du X, et al. (2001) Crystal structure and mechanism of catalysis of a pyrazinamidase from Pyrococcus horikoshii. Biochemistry 40: 14166-14172.

Gazzaniga F, Stebbins R, Chang SZ, McPeek MA, Brenner C (2009) Microbial NAD metabolism: lessons from comparative genomics. Microbiol Mol Biol Rev 73: 529-541.

Gill DM, Pappenheimer, Jr AM, Brown R, Kurnick JT (1969) Studies on the mode of action of diphtheria toxin. VII. Toxin-stimulated hydrolysis of nicotinamide adenine dinucleotide in mammalian cell extracts. J Exp Med 129:1-21.

Hofmann D, Wirtz A, Santial-Schuvel B, Disko U, Pohl M (2010) Structure elucidation of the thermal degradation products of the nucleotide cofactors NADH and 
NADPH by nano-ESI-FTICR-MS and HPLC-MS. Anal Bioanal Chem 398: 2803-2811.

462

463

464

465

Imai S, Armstrong CM, Kaeberlein M, Guarente L (2000) Transcriptional silencing and longevity protein Sir2 is an NAD-dependent histone deacetylase. Nature 403: 795-800.

Iwamoto S, et al. (2007) Use of an Escherichia coli recombinant producing thermostable polyphosphate kinase as an ATP regenerator to produce fructose 1,6-diphosphate. Appl Environ Microbiol 73: 5676-5678.

Jena BK, Raj R (2006) Electrochemical biosensor based on integrated assembly of dehydrogenase enzymes and gold nanoparticles. Anal Chem 78: 6332-6339.

Kameda A, et al. (2001) A novel ATP regeneration system using polyphosphate-AMP phosphotransferase and polyphosphate kinase. J Biosci Bioeng 91: 557-563.

Kataoka M, et al. (2003) Novel bioreduction system for the production of chiral alcohols. Appl Microbiol Biotechnol 62: 437-445.

Krutsakorn B, et al. (2013) In vitro production of n-butanol from glucose. Metab Eng 20: 84-91.

Luo H-B, et al. (2010) Crystal structure and molecular modeling study of $N$-carbamoylsarcosine amidase Ta0454 from Thermoplasma asidophilum. J Struct Biol 169: 304-311.

Martin PR, Shea RJ, Mulks MH (2001) Identification of a plasmid-encoded gene from Haemophilus ducreyi which confers NAD independence. J Bacteriol 183: $1168-1174$.

Motomura K, et al. (2014) A new subfamily of polyphosphate kinase 2 (Class III PPK2) catalyzes both nucleoside monophosphate phosphorylation and nucleoside 

diphosphate phosphorylation. Appl Environ Microbiol 80: 2602-2608.

485

486

487

488

Ninh PH, Honda K, Sakai T, Okano K, Ohtake H (2015) Assembly and multiple gene expression of thermophilic enzymes in Escherichia coli for in vitro metabolic engineering. Biotechnol Bioeng 112: 189-196.

Ooga T, Yoshiba S, Nakagawa N, Kuramitsu S, Masui R (2005) Molecular mechanism of the Thermus thermophilus ADP-ribose pyrophosphate from mutational and kinetic studies. Biochemistry 44: 9320-9326.

Owusu RK, Cowan DA (1989) Correlation between microbial protein thermostability and resistance to denaturation in aqueous:organic solvent two-phase systems. Enzyme Microb Technol 11: 568-574.

Resnick SM, Zehnder AJB (2000) In vitro ATP regeneration from polyphosphate and AMP by polyphosphate: AMP phosphotransferase and adenylate kinase from Acinetobacter johnsonii 210A. Appl Environ Microbiol 66: 2045-2051.

Restiawaty E, et al. (2011) Feasibility of thermophilic adenosine triphosphate-regeneration system using Thermus thermophilus polyphosphate kinase. Process Biochem 46: 1747-1752.

Rollin JA, Tam TK, Zhang Y-HP (2013) New biotechnology paradigm: cell-free biosystems for biomanufacturing. Green Chem 15: 1708-1719.

Rollin JA, et al. (2014a) High-yield hydrogen production from biomass by in vitro metabolic engineering: Mixed sugars coutilization and kinetic modeling. Proc Natl Acad Sci USA 112: 4964-4969.

Rollin JA, Ye X, del Campo JM, Adams, MWW, Zhang Y-HP (2014b) Novel hydrogen bioreactor and detection apparatus. Adv Biochem Eng Biotechnol 152, 35-51.

Satoh T, Kato J, Takiguchi N, Ohtake H, Kuroda A (2004) ATP amplification for 

Biotech Biochem 68: 1216-1200.

Stekhanova TN, et al. (2014) Nicotinamidase from the thermophilic archaeon Acidilobus saccharovorans: Structural and functional characteristics. Biochemistry (Moscow) 79: 54-61.

Stuermer R, Hauer B, Hall M, Faber K (2007) Asymmetric bioreduction of activated $\mathrm{C}=\mathrm{C}$ bonds using enoate reductases from the old yellow enzyme family. Curr Opin Chem Biol 11: 203-213.

Tachibana S, Suzuki M, Asano Y (2006) Application of an enzyme chip to the microquantification of L-phenylalanine. Anal Biochem 359: 72-78.

Urlacher VB, Lutz-Wahl S, Schmid RD (2004) Microbial P450 enzymes in biotechnology. Appl Microbiol Biotechnol 64: 317-325.

Wilkinson A, Day J, Bowater R (2001) Bacterial DNA ligases. Mol Microbiol 40: 1241-1248.

Wu JT, Wu LH, Knight JA (1986) Stability of NADPH: Effect of various factors on the kinetics of degradation. Clin Chem 32: 314-319.

$\mathrm{Wu} \mathrm{X}$, et al. (2011) Application or a novel thermostable NAD(P)H oxidase from hyperthermophilic archaeon for the regeneration of both $\mathrm{NAD}^{+}$and $\mathrm{NADP}^{+}$. Biotechnol Bioeng 109: 53-62.

Yamaguchi F, et al. (2002) Stable ammonia-specific NAD synthetase from Bacillus stearothermophilus: purification, characterization, gene cloning, and applications. Biosci Biotechnol Biochem 66: 2052-2059.

Ye X, et al. (2012) Synthetic metabolic engineering-a novel, simple technology for designing a chimeric metabolic pathway. Microb Cell Fact 11: 120. 
532 Ye X, Honda K, Morimoto Y, Okano K, Ohtake H (2013) Direct conversion of glucose 533 to malate by synthetic metabolic engineering. J Biotechnol 164: 34-40.

534 Yokoyama S, et al. (2000) Structural genomics projects in Japan. Nat Struct Biol 7, 535 943-945.

536 Yoshiba S, et al. (2004) Structural insights into the Thermus thermophilus ADP-ribose $537 \quad$ pyrophosphatase mechanism via crystal structures with the bound substrate and $538 \quad$ metal. J Biol Chem 279: 37163-37174.

539 
Figure legends

541

542 Fig. 1. Thermal degradation of $\mathrm{NAD}^{+} . \mathrm{NAD}^{+}(4 \mathrm{mM})$ was incubated at $60^{\circ} \mathrm{C}$ in $400 \mathrm{mM}$ HEPES-NaOH (pH8.0). Samples were taken at every 1-h intervals and analyzed by HPLC. The time courses of the concentrations of $\mathrm{NAD}^{+}$(filled square), nicotinamide (open circle), and ADP-ribose (open square) are shown. The assays were performed in triplicate; mean \pm standard deviations (error bars) are depicted.

Fig. 2. Possible routes for the salvage synthesis of $\mathrm{NAD}^{+}$from nicotinamide. The enzyme that was not identified in this study is shown by a white arrow. The nicotinamide-salvage route constructed in this study is highlighted in gray box.

Fig. 3. Design of the in vitro pathway for the salvage synthesis of $\mathrm{NAD}^{+}$from nicotinamide and ADP-ribose. Blue arrows indicate ATP regenerating reactions, which are shown in detail in the inner panel.

Fig. 4. Inhibitory effect of $\mathrm{NAD}^{+}$on $\mathrm{NaPRT}_{\mathrm{Tt}}$ activity. The enzyme at an appropriate amount was incubated at $60^{\circ} \mathrm{C}$ in the reaction mixture consisting of $400 \mathrm{mM}$ HEPES-NaOH (pH 8.0), $60 \mathrm{mM} \mathrm{NH} \mathrm{NH}_{4} \mathrm{Cl}, 10 \mathrm{mM} \mathrm{MgCl} 2,1 \mathrm{mM}$ polyphosphate, $1 \mathrm{mM}$ PRPP, $1 \mathrm{mM}$ nicotinamide, and indicated concentrations of $\mathrm{NAD}^{+}$. The mixture was analyzed by HPLC and the enzyme activities were calculated from the concentration of $\mathrm{NaMN}$ formed by the enzyme reaction. The assays were performed in triplicate; mean \pm 
564 Fig. 5. In vitro salvage synthesis of $\mathrm{NAD}^{+} . \mathrm{NAD}^{+}(4 \mathrm{mM})$ was incubated at $60^{\circ} \mathrm{C}$ in 400 $565 \mathrm{mM}$ HEPES-NaOH (pH 8.0) with (closed square) and without (open square) the 566 enzymes. Samples were taken at every 3-h intervals, ultrafiltrated, and then analyzed by 567 HPLC. The assays were performed in triplicate; mean \pm standard deviations (error bars) 568 are depicted 
Figure 1

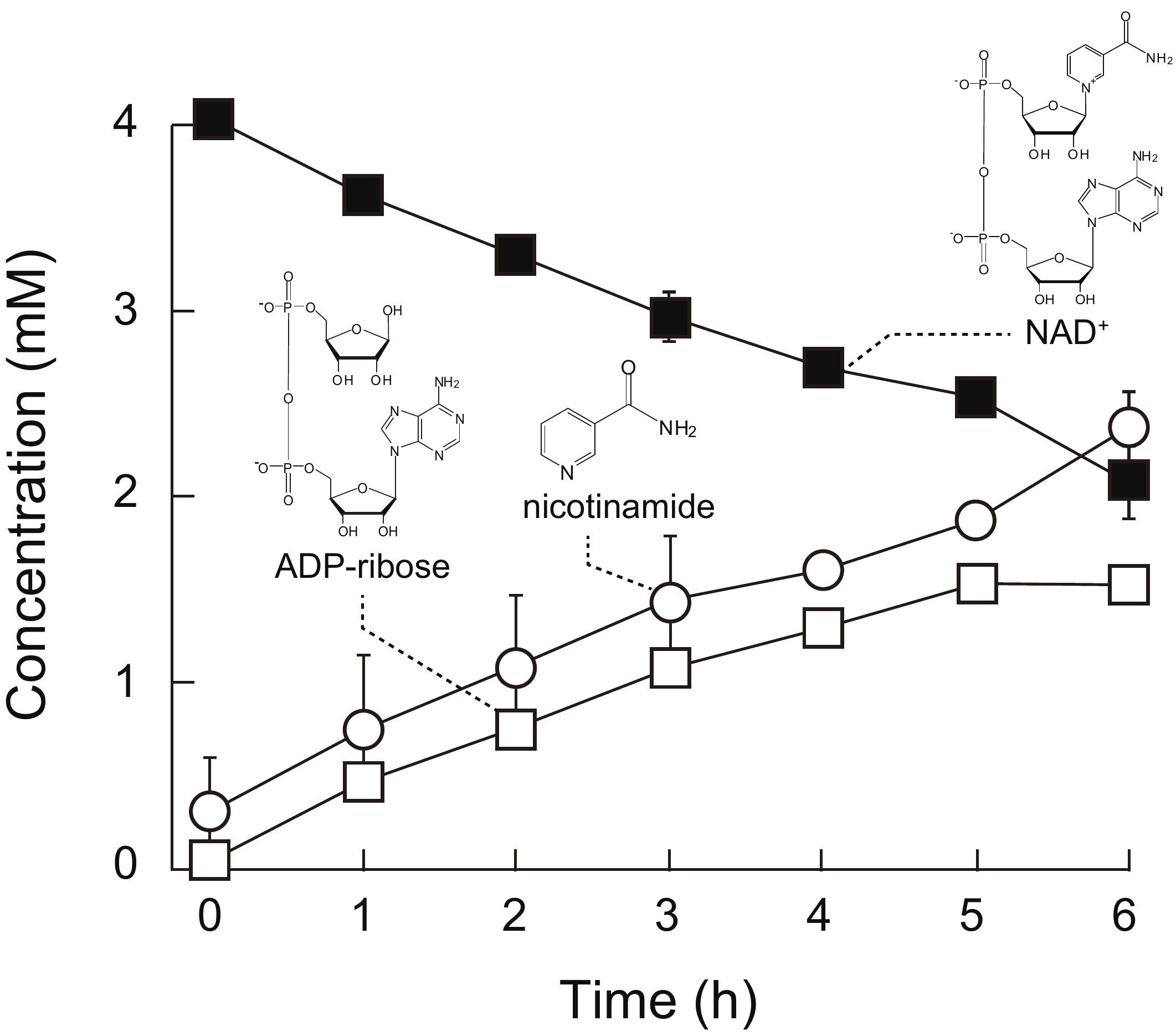




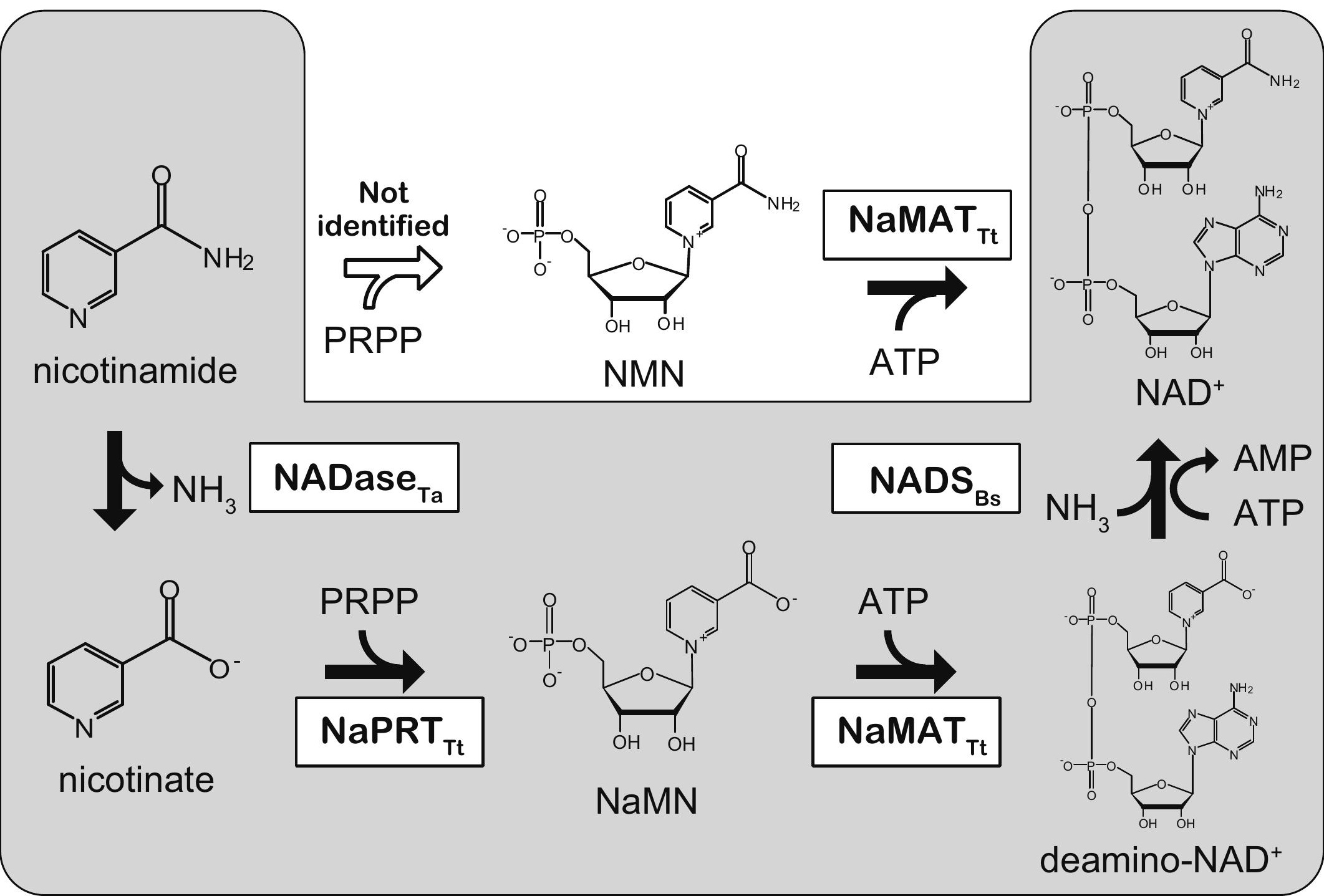



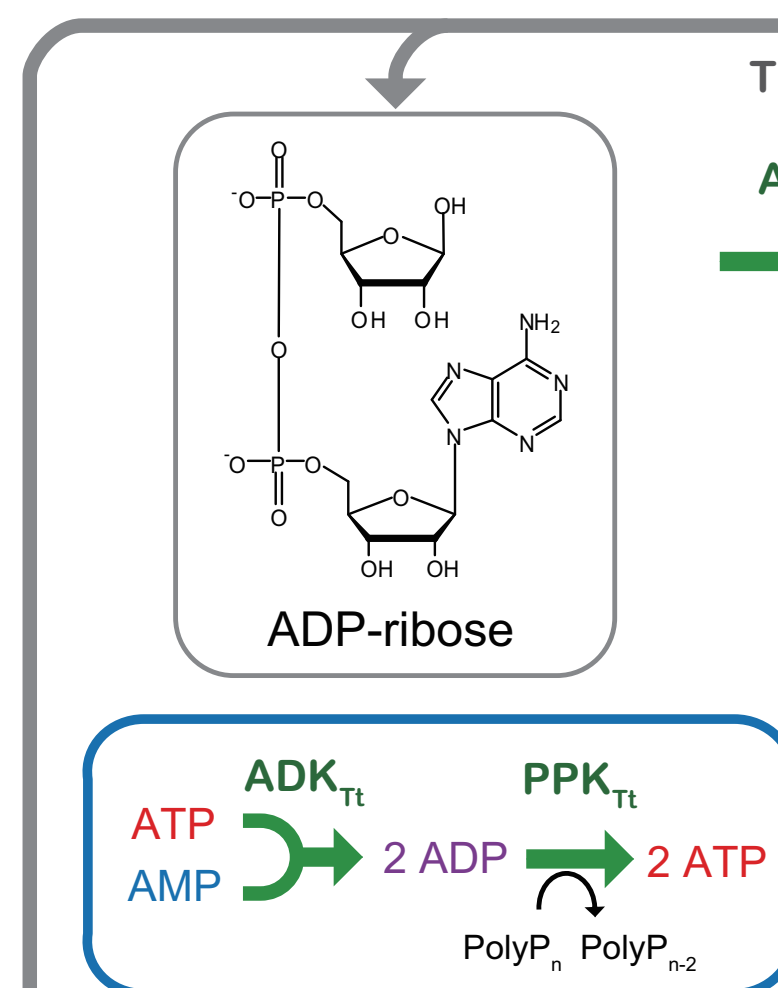

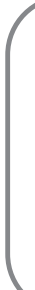<smiles>NC(=O)c1cccnc1</smiles>

nicotinamide
Thermal decomposition

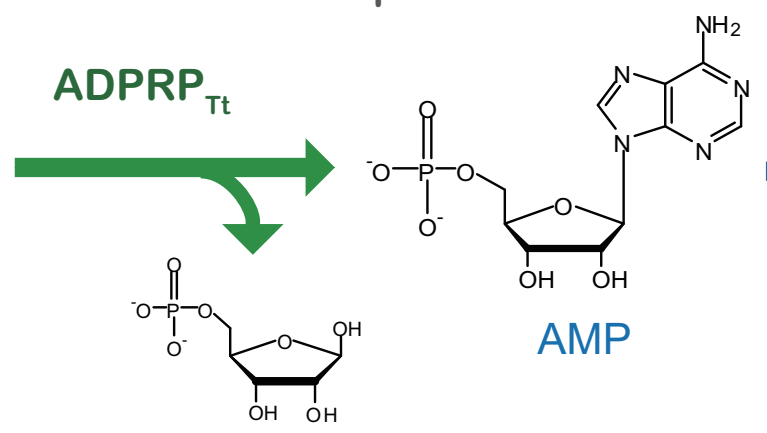

R5P

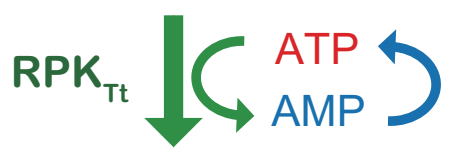

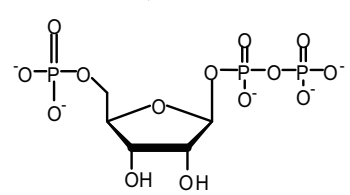

PRPP

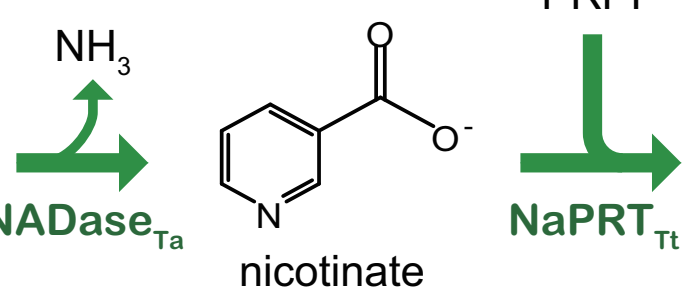

nicotinate

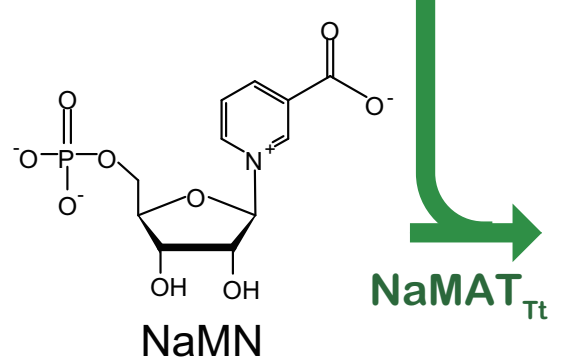

NaMN

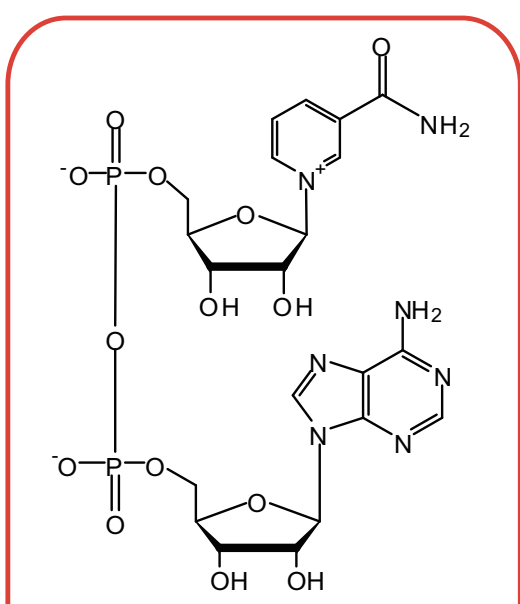

$\mathrm{NAD}^{+}$
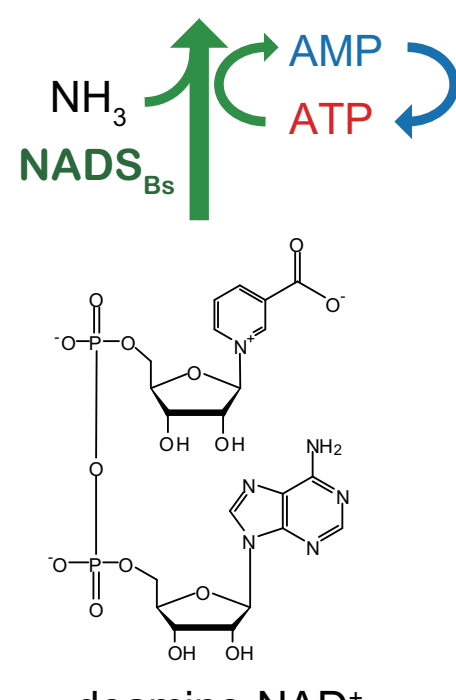

deamino-NAD+ 


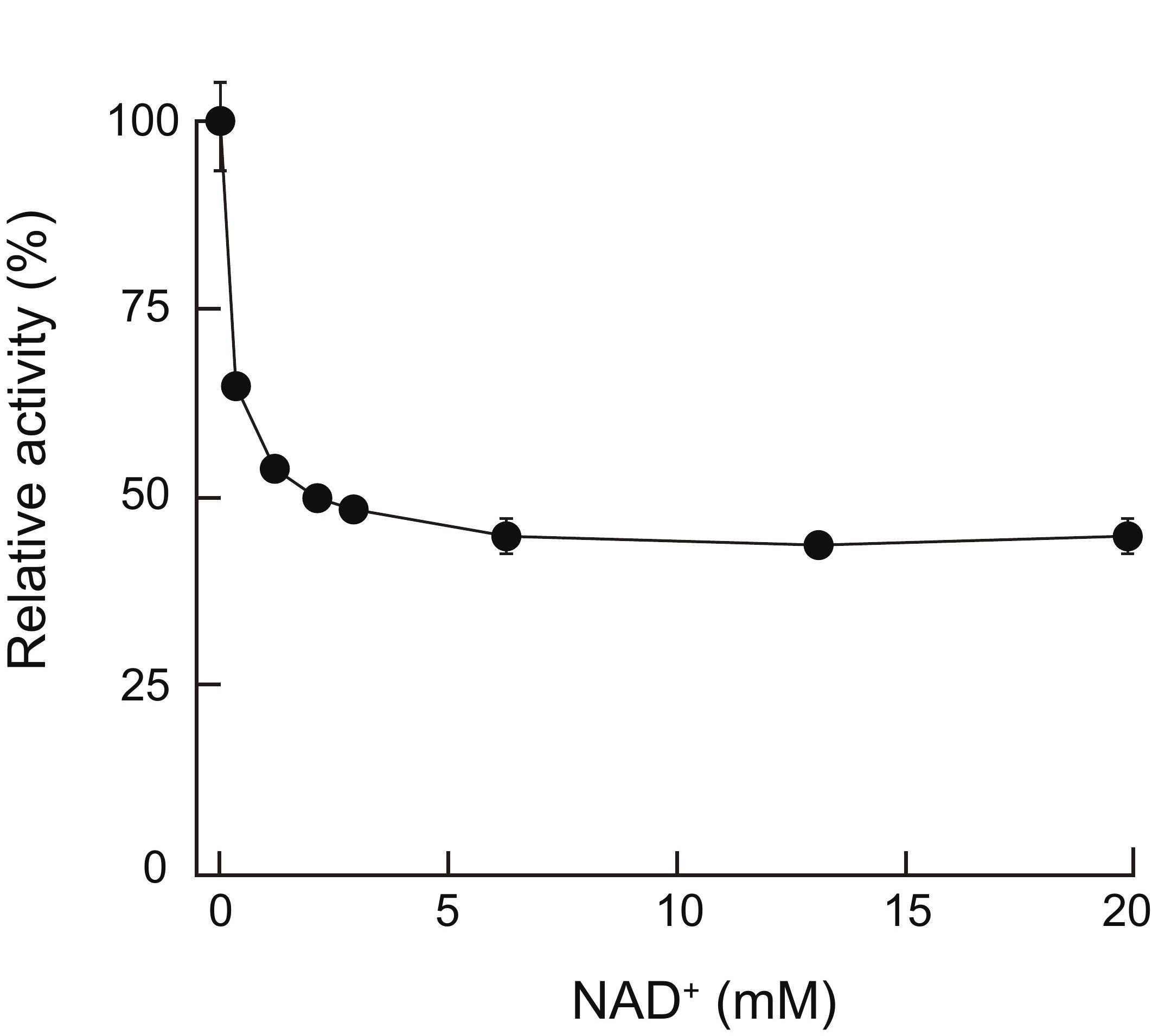

$\mathrm{NAD}^{+}(\mathrm{mM})$
Figure 4

\section{Figure 4}

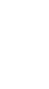

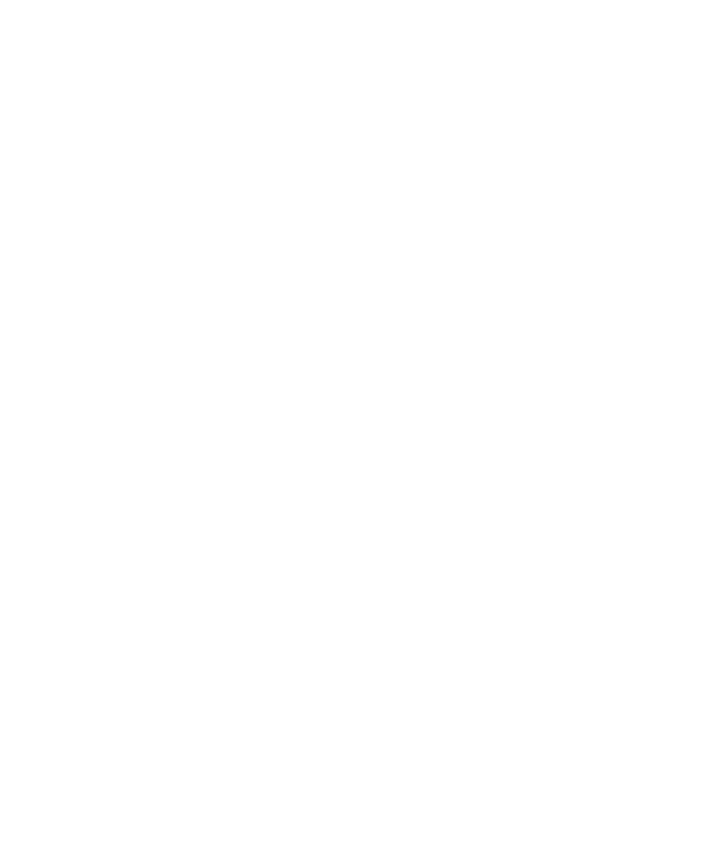




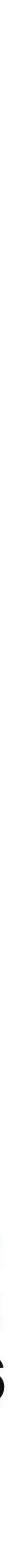

Figure 5 